\title{
An Integrative Approach of the Fissure Completeness Score and Chartis Assessment in Endobronchial Valve Treatment for Emphysema
}

This article was published in the following Dove Press journal: International Journal of Chronic Obstructive Pulmonary Disease

\author{
Karin Klooster ${ }^{\mathrm{I}} *$ \\ T David Koster ${ }^{1, *}$ \\ Christoph Ruwwe- \\ Glösenkamp ${ }^{2}$ \\ Dorothea Theilig ${ }^{3}$ \\ Felix Doellinger $\mathbb{I D}^{3}$ \\ Jacopo Saccomanno ${ }^{2}$ \\ Huib AM Kerstjens (D) \\ Dirk-Jan Slebos' \\ Ralf-Harto Hübner ${ }^{2}$ \\ 'University of Groningen, University \\ Medical Center Groningen, Department \\ of Pulmonary Diseases, Groningen, the \\ Netherlands; ${ }^{2}$ Charité \\ Universitätsmedizin Berlin, Campus \\ Virchow Klinikum, Department of \\ Pneumology, Berlin, Germany; ${ }^{3}$ Charité \\ Universitätsmedizin Berlin, Campus \\ Virchow Klinikum, Department of \\ Radiology, Berlin, Germany \\ *These authors contributed equally to \\ this work
}

\begin{abstract}
Purpose: Lung volume reduction using one-way endobronchial valves is a bronchoscopic treatment for patients with severe emphysema without collateral ventilation between the treatment target lobe and the ipsilateral lobe(s). CT-scan fissure analysis is often used as a surrogate to predict the absence of collateral ventilation. We aimed to evaluate the predictive value of the fissure completeness score (FCS) compared to the functional Chartis measurement of collateral ventilation and to provide cut-off values of the FCS in patient selection.
\end{abstract}

Patients and Methods: Multicenter study in patients eligible for treatment with one-way valves. The FCS was calculated by quantitative CT analysis (Thirona, the Netherlands) and compared to status of interlobar collateral ventilation measured with Chartis system (PulmonX, USA). Thresholds were calculated for the predictive values of the presence of collateral ventilation.

Results: An FCS $>95 \%$ of the left major fissure had a positive predictive value (PPV) of 91\%, with 1 in 11 fissures demonstrating collateral ventilation with Chartis measurement, whereas an FCS of $\leq 80 \%$ had a negative predictive value (NPV) of $100 \%$ for the presence of collateral ventilation. For the right major fissure, the NPV was $100 \%$ for an FCS $\leq 90 \%$, but $69.7 \%$ for the right upper lobe fissure.

Conclusion: Quantitative CT analysis is recommended in all patients evaluated for endobronchial valves. Patients with incomplete fissures (left major fissure: FCS $<80 \%$; right major fissure: $<90 \%$ ) can be excluded from Chartis measurement and endobronchial valve treatment. In patients with more complete fissures, the FCS is not specific enough for endobronchial valve treatment decisions. In this case, additional Chartis measurements are always recommended in the right lung. For the left lung, Chartis assessments may be omitted if the FCS is $>95 \%$.

Keywords: COPD, lung volume reduction, fissure, collateral ventilation, CT scan

\section{Introduction}

Bronchoscopic lung volume reduction with endobronchial valves (EBV) is an additional treatment option for patients with severe emphysema and hyperinflation. The purpose of this treatment is to achieve volume reduction of the most diseased lobe. During this treatment, one-way endobronchial valves are placed in all (sub-)segments of the most diseased lobe to achieve lobar occlusion. This treatment has been proven effective in multiple studies, and provides clinically meaningful benefits in lung function, dyspnea, quality of life and exercise tolerance in a selected group of patients with chronic obstructive pulmonary disease (COPD). ${ }^{1-8}$
Correspondence: Karin Klooster Email k.klooster@umcg.nl 
However, treatment is only effective in carefully selected patients. The most important factor for an effective treatment is the absence of interlobar collateral ventilation. If collateral ventilation is present between the target lobe and adjacent ipsilateral lobe(s), the placement of oneway valves will not achieve the desired atelectasis, resulting in no clinically meaningful benefit. ${ }^{9-13}$

Collateral ventilation can be functionally measured using the Chartis system ${ }^{\circledR}$ (PulmonX Inc., Redwood City, CA, USA). ${ }^{12,14,15}$ With this method, a catheter with a balloon component at the end is inflated in the entrance of the airways of the target treatment lobe. The Chartis console then measures the expiratory airflow from this lobe. If airflow persists after balloon occlusion, this indicates that there is collateral ventilation. However, if the flow decreases over time and gradually stops, this indicates the absence of collateral ventilation and these patients are suitable for treatment with valves.

Although Chartis measurement proved to be a valuable and reliable tool, it is a time-consuming bronchoscopic procedure if used in all patients with severe hyperinflation regardless if they will receive valves, as many have collateral ventilation. If this measurement could be avoided in patients with certain presence (or absence) of collateral ventilation, this would save burden, time and costs.

An indirect and non-invasive method for assessment of collateral ventilation is the fissure completeness score (FCS) calculated on high-resolution computed tomography (HRCT) using quantitative CT analysis (QCT). A high score indicates that an interlobar fissure is (nearly) complete and that the likelihood of having collateral ventilation is small, though not absent. ${ }^{15}$ Until recently, a fissure was defined as complete on HRCT scan if the fissure integrity was more than 90 percent. ${ }^{1-3,14,16-18}$ This value is relatively arbitrary and studies found rather variable relations between the FCS and treatment outcome. A recent study supports the use of combining the fissure completeness scores and Chartis measurements and advised a Chartis measurement in patients with FCS between $80 \%$ and $95 \%$, exclude patients with FCS $<80 \%$ and treat patients with FCS $>95 \% .{ }^{15}$ There is a need for confirmation regarding these cut-offs, given the importance of accurately selecting the responder patients. ${ }^{12,13}$ Although Chartis measurement is clinical practice in many clinics, there are recent studies that advocate the use of the fissure cut-off score of $90 \%$ only. ${ }^{19,20}$ However, more accurate selection of responder patients prevents unnecessary procedures, non-beneficial treatments and extra costs in patients with collateral ventilation. Therefore, we performed a study to correlate the FCS to the Chartis assessment. In this study, we investigated in which patients additional Chartis assessments are recommended or can be avoided with detailed quantitative assessment of the FCS on HRCT. Additionally, we evaluated costs involved in adding Chartis assessment.

\section{Patients and Methods Study Design}

This is a retrospective multicenter study comparing outcomes of the quantitative assessment of the FCS on HRCT with Chartis measurements in a routine clinical care setting in the University Medical Center Groningen, the Netherlands and in the Charité University Clinic, Berlin, Germany. The study was conducted in accordance with the declaration of Helsinki, and all patients provided written informed consent regarding their treatment and use of their data for future scientific purposes, which was approved by the medical ethics committee of the University Medical Center Groningen (METc2016.483) and of the Charité University Clinic (EA2/149/17). All data was anonymized and treated with confidentiality according to GCP guidelines.

Patients were selected for treatment based on their primary assessment and work-up including a pulmonary function test, high-resolution CT scan (maximum $1 \mathrm{~mm}$ slice thickness) and QCT analysis with a target lobe for treatment with (near) complete fissures between the target lobe and the ipsilateral lobe. During the valve procedure, Chartis is performed and if there is no collateral ventilation, valves are placed. All patients who were scheduled for a valve treatment procedure and who have signed an informed consent form were included in this study. The Chartis measurement was performed for the target lobe fissure first, and preferably all other fissures to gather information regarding the presence or absence of collateral ventilation over the other fissures.

\section{Assessment of FCS on HRCT}

QCT analysis was performed on all baseline scans using Thirona LungQ version 1.0.0 (Thirona BV, Nijmegen, the Netherlands) to assess fissure completeness and lobar tissue destruction at baseline for each subject. The methods for QCT analysis and calculation of the FCS have been described previously. ${ }^{15}$ In each chest CT scan, the lungs, fissures and lobes were automatically segmented and afterwards visually 
checked and edited by trained medical analysts. Based on these results, FCS was computed for each lobe. This is defined as the percentage of the lobar boundaries defined by a fissure.

\section{Chartis Measurement}

Collateral ventilation was assessed as previously described using the Chartis system. ${ }^{21}$ The measurements were performed under either spontaneous breathing with conscious sedation (Berlin) or under general anesthesia (Groningen) using a flexible therapeutic bronchoscope. The Chartis balloon was placed in the entrance of the upper lobe and/or the lower lobe from the right lung and the left lung.

In the right lung, the major fissure can be measured in the lower lobe or in the upper lobe while blocking the middle lobe with a Fogarty balloon or Watanabe spigot. The right upper lobe fissure consists of the minor fissure and a part of the major fissure (Figure 1) and is measured with Chartis in the right upper lobe. In the left lung, the major fissure can be measured in the lower lobe or in the upper lobe. Preferably, the target lobe was chosen to be measured first. Chartis results were defined as presence of collateral ventilation $\left(\mathrm{CV}_{\text {pos }}\right)$, absence of collateral ventilation $\left(\mathrm{CV}_{\text {neg }}\right)$, or "not conclusive", if the status of collateral ventilation could not be concluded. These assessments include the "low flow" or "no flow phenotype" (also known as "collapse phenotype") and the "low plateau phenotype" as recently reported. ${ }^{22,23}$

\section{Statistical Analyses}

Patients were included in the analysis if they underwent Chartis assessments and had an evaluable baseline HRCT. The FCS was evaluated for its ability to predict the Chartis outcome, for which a receiver operating characteristics (ROC) curve was created. Sensitivity, specificity, positive and negative predictive values were calculated for each FCS. We aimed to calculate two FCS thresholds for both major fissures and the right upper lobe fissure. The first lower threshold of FCS was set to minimize the number of false negatives (incomplete FCS without presence of collateral ventilation). The second higher threshold of FCS was defined to minimize the number of false positives (complete FCS but presence of collateral ventilation). This will result in three groups for each fissure: 1) incomplete fissure (less than lower FCS threshold); 2) complete fissure (more than higher FCS threshold); 3) partially complete fissure (FCS between two thresholds). IBM SPSS Statistics, version 23.0 (Armonk, USA) was used for all analyses.

\section{Results \\ Study Patients}

In total, 240 patients with COPD and eligible for EBV treatment were included, and the FCS of the right major fissure, right upper lobe fissure and left major fissure (Figure 1) were measured with QCT analysis. In these patients, 429 fissures were categorized as "presence of collateral ventilation between

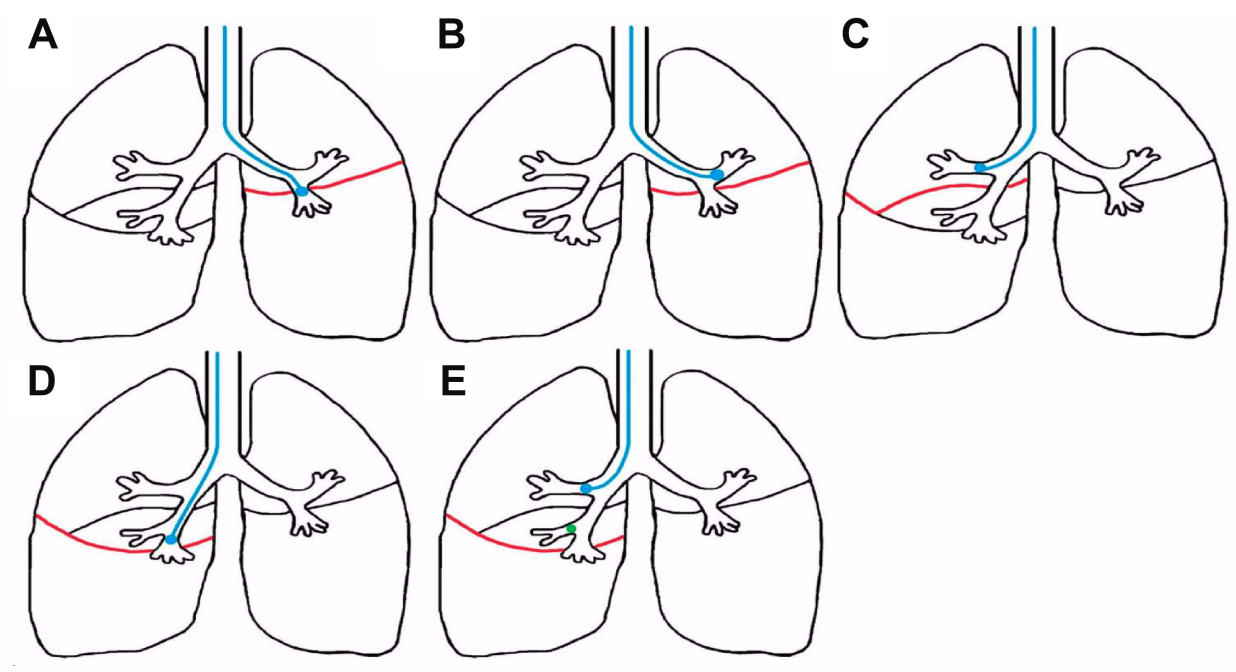

Figure I Measurement of collateral flow with Chartis. (A) and (B) Collateral flow over the left major fissure (red) is measured by a balloon occluding the entrance of the left lower lobe (A) or the left upper lobe (B). (C) Collateral flow over the right upper lobe fissure is measured in the right upper lobe. This fissure consists of the minor fissure and a part of the right major fissure (red). (D) Collateral flow over the right major fissure (red) is measured by a balloon occluding the entrance of the right lower lobe. If this is unsuccessful, (E) collateral flow can be measured in the right upper lobe while the middle lobe is also occluded with a Fogarty balloon or a Watanabe spigot (green). 
EBV target lobe and ipsilateral lobe" $\left(\mathrm{CV}_{\mathrm{pos}}\right)$ or "absence of collateral ventilation between EBV target lobe and ipsilateral lobe" $\left(\mathrm{CV}_{\text {neg }}\right)$ with Chartis assessments. The baseline characteristics of the included subjects are presented in Table 1.

\section{Assessment of the Fissure Completeness Score on HRCT and Chartis Assessment}

The median FCS of the right major fissure was 97.1\% (range 60.2-100\%), right upper lobe fissure $85.3 \%$ (range 23.4$100 \%$ ) left major fissure 99.9\% (range 49.7-100\%). Chartis measurement was performed under conscious sedation in 113 patients and under general anesthesia in 127 patients. Chartis assessment of the right major fissure was performed in 106 patients (44\%). Of these, 41 patients $(39 \%)$ had presence of collateral ventilation and 65 patients $(61 \%)$ had absence of collateral ventilation. The right upper lobe fissure was conclusively measured in 115 patients: 65 patients (57\%) were $\mathrm{CV}_{\text {pos }}$ and 50 patients (43\%) were $\mathrm{CV}_{\text {neg. }}$ Chartis assessment over the left major fissure was successfully performed in 208 patients of whom 40 were $\mathrm{CV}_{\text {pos }}$ (19\%) and 168 were $\mathrm{CV}_{\text {neg }}(81 \%)$.

\section{Fissure Completeness Score versus Chartis Outcome}

The median FCS was significantly higher in patients without collateral ventilation $(\mathrm{p}<0.001)$ in all groups, see Table 2 . Figure 2 shows the percentage of patients with or without collateral ventilation per fissure divided into subgroups of FCS. The predictive values per fissure and FCS are shown in Table 3.

Right major fissure: The area under the curve (AUC) of the ROC-curve is 0.789 (Figure 3A). Lower cut off: FCS of

Table I Baseline Characteristics

\begin{tabular}{|c|c|c|}
\hline \multicolumn{2}{|l|}{ Patients (N) } & 240 \\
\hline \multicolumn{2}{|l|}{ Female $(\mathrm{N})$} & | 42 (59\%) \\
\hline \multicolumn{2}{|l|}{ Age (years) } & $66 \pm 8$ \\
\hline \multicolumn{2}{|l|}{ BMI $\left(\mathrm{kg} / \mathrm{m}^{2}\right)$} & $24 \pm 4$ \\
\hline \multicolumn{2}{|l|}{ Pack years } & $45 \pm 24$ \\
\hline Lung function & $\begin{array}{l}\text { FEV } \text { (\%pred) } \\
\text { RV (\%pred) } \\
\text { TLC (\%pred) } \\
\text { DLCO (\%pred) }\end{array}$ & $\begin{array}{l}27 \pm 7 \\
232 \pm 5 \mid \\
|3| \pm 18 \\
30 \pm 12\end{array}$ \\
\hline
\end{tabular}

Abbreviations: BMI, body mass index; $\mathrm{FEV}_{\mathrm{l}}$, forced expiratory volume; RV, residual volume; TLC, total lung capacity; DLCO, diffusing capacity of the lung for carbon monoxide.
Table 2 Fissure Completeness Score Compared to Chartis Measurement

\begin{tabular}{|l|l|l|l|l|}
\hline \multirow{2}{*}{ FCS } & \multicolumn{2}{l|}{ CV Positive } & \multicolumn{2}{l|}{ CV Negative } \\
\cline { 2 - 5 } & Median & Range & Median & Range \\
\hline Right major fissure & 94.8 & $60.2-100$ & 98.9 & $91.1-100$ \\
Right upper lobe fissure & 83.4 & $23.4-76.6$ & 97.2 & $25.1-100$ \\
Left major fissure & 91.4 & $49.7-100$ & 100 & $82.9-100$ \\
\hline
\end{tabular}

Abbreviations: FCS, fissure completeness score; CV positive, presence of collateral ventilation; CV negative, absence of collateral ventilation.

$\leq 90 \%$ has a negative predictive value of $100 \%$. Upper Cut off: patients with FCS $>95 \%$ have a positive predictive value of $73.7 \%$, compared to $85.7 \%$ in patients with a fissure integrity of $100 \%$.

Right Upper Lobe Fissure: The AUC of the ROCcurve is 0.767 (Figure 3B). Lower Cut off: of the 24 patients with FCS $\leq 75 \%, 3$ were CV negative. The FCS of these patients were $75.0 \%, 55.6 \%$ and $25.1 \%$. Upper Cut off: the positive predictive value of FCS $>95 \%$ is $73.2 \%$, and $81.3 \%$ with an FCS of $100 \%$. Even with an FCS of $100 \%, 18.8 \%$ of the patients showed evidence of collateral ventilation, compared to $26.8 \%$ with an FCS of $>95 \%$.

Left Major Fissure: The AUC of the ROC-curve is 0.829 (Figure 3C). Lower Cut off: an FCS of $\leq 80 \%$ has a negative predictive value of $100 \%$. Upper Cut off: patients with $\mathrm{FCS}>95 \%$ have a positive predictive value of $91.1 \%$, compared to $92.8 \%$ with a fissure integrity of $100 \%$.

\section{Costs}

To analyze the cost effectiveness of treating patients based on FCS alone or in combination with additional Chartis measurements, a costs-analysis was performed based on published data by Hartman et al, assuming 100 hypothetical patients. $^{24}$ Based on the predictive values of the FCS, combining FCS and Chartis assessments before endobronchial valve treatment is always cost-effective in both fissures in the right lung (Figure 4). However, in regard to the left major fissure, it is cost-effective to treat without an additional Chartis measurement using an FCS $>95 \%$.

\section{Discussion}

Patients with severe emphysema can be successfully treated with endobronchial valves. ${ }^{1,2,6-8,18}$ Careful patient selection is crucial, and the absence of collateral ventilation is one of the most important predictive factors for 
Right Major Fissure

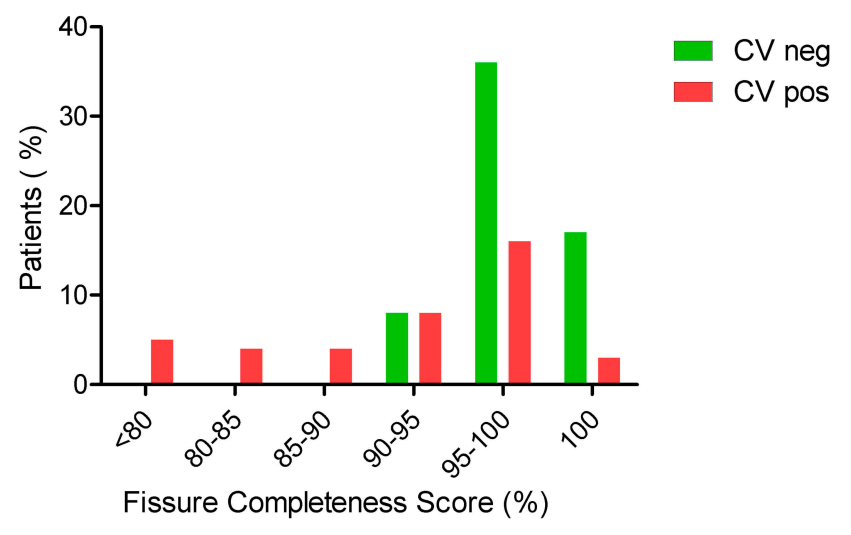

Right Upper Lobe Fissure

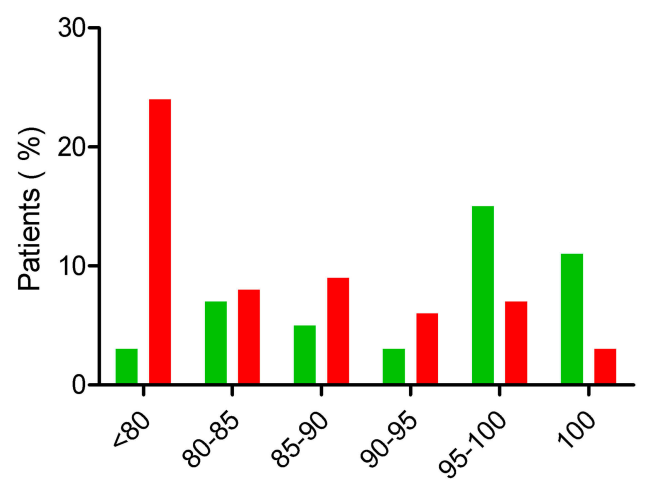

Fissure Completeness Score (\%)

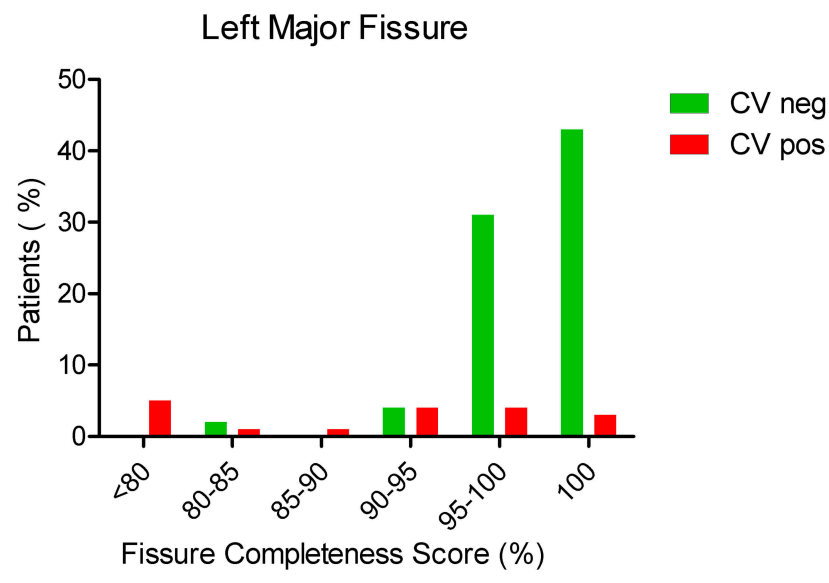

Figure 2 Distribution of collateral ventilation. Percentage of patients with $\mathrm{CV}_{\text {neg }}$ or $\mathrm{CV}_{\text {pos }}$ compared to the fissure completeness score of the right major fissure, the right upper lobe fissure and the left major fissure. Number of patients: Right Major Fissure: 106; Right Upper Lobe Fissure: II5; Left Major Fissure: 208.

Abbreviations: $\mathrm{CV}_{\text {pos }}$, presence of collateral ventilation; $\mathrm{CV}_{\text {neg }}$, absence of collateral ventilation.

a successful treatment. Valves placed in patients who turn out to have collateral ventilation are a burden to patients, treating teams and healthcare costs. We show in which patients additional assessments of collateral ventilation can lead to improved outcomes and cost savings.
The importance of collateral ventilation and the role of the FCS was acknowledged soon after the first treatments with endobronchial valves. ${ }^{18}$ QCT analysis provides an easy and non-invasive tool to assess the FCS as a surrogate for collateral ventilation. The FCS is predictive for the presence or absence or collateral ventilation, which is frequently used to preselect patients for treatment. However, although a correlation of FCS with the likelihood of collateral ventilation is evident, the degree of the correlation remains subject to discussion. Various studies used a cut-off value of $90 \%$ to define a fissure as complete. $^{3,14,16,18,20}$ However, as our study shows, even with a fissure integrity of over $90 \%$, a significant number of patients still have collateral ventilation and will not benefit from endobronchial valve treatment.

Two recently published randomized controlled trials treated patients based on FCS $>90 \%$ alone, the EMPROVE and the REACH trial. ${ }^{19,20}$ They showed an FEV1 improvement of $>15 \%$ in $37.2 \%$ and $41 \%$ of the patients, an RV reduction of 402 and $420 \mathrm{~mL}$ and a target lobe volume reduction of $>350 \mathrm{~mL}$ reduction in 74.5 and $66.1 \%$, respectively. However, the mean FCS in the REACH trial was $97.8 \%$ and the mean FCS of the EMPROVE trial is not known. The effect in a subgroup of patients with fissures between $90 \%$ and $95 \%$ or how much of these patients are treated are not given. The LIBERATE and the TRANSFORM trial treated patients based on the presence of collateral ventilation measured by Chartis and showed an improvement of FEV1 $>15 \%$ in $47.7 \%$ and $>12 \%$ in $56.3 \%$, the TLV-reduction $>350 \mathrm{~mL}$ was $89.9 \%$ at 12 months and 89.9 at 6 weeks, respectively. ${ }^{5,8}$ Furthermore, there is a difference in the occurrence of pneumothorax between these methods. The trials that treated patients only after the exclusion of collateral ventilation based on Chartis measurement reported a pneumothorax incidence between $26 \%$ and $29 \%,{ }^{5,6,8}$ which is significantly higher than the rate of $4-14 \%$ reported in studies using only the $90 \%$ FCS cutoff. $19,20,25$ A higher pneumothorax incidence might indicate a larger treatment effect. Therefore, the effect appears to be more pronounced in studies using the Chartis measurement as the ultimate patient selection tool.

An earlier study suggested that the combination of Chartis and fissure analysis provides a useful workflow in patients eligible for endobronchial lung volume reduction by division in three groups. ${ }^{15}$ Patients with incomplete fissures (FCS $<80 \%$ ) can be excluded from further valve treatment evaluation. Partially complete fissures (FCS between $80 \%$ and $95 \%$ ) should be assessed with Chartis prior to treatment and high FCS $(>95 \%)$ can be treated without additional Chartis 
Table 3 Predictive Values per Fissure Completeness Score

\begin{tabular}{|c|c|c|c|c|c|c|c|}
\hline \multicolumn{8}{|c|}{ Right Major Fissure $(\mathrm{N}=106)$} \\
\hline FCS & $C V_{\text {neg }}$ & $\mathrm{CV}_{\text {pos }}$ & Sens & Spec & PPV & NPV & Number of Chartis Needed* \\
\hline$>80$ & $64.4 \%$ & $35.6 \%$ & 12.2 & 96.0 & 64.4 & 100.0 & 2.8 \\
\hline$>83$ & $65.0 \%$ & $35.0 \%$ & 14.6 & 100.0 & 65.0 & 100.0 & 2.9 \\
\hline$>85$ & $67.0 \%$ & $33.0 \%$ & 22.0 & 100.0 & 67.0 & 100.0 & 3.0 \\
\hline$>90$ & $69.9 \%$ & $30.1 \%$ & 31.7 & 100.0 & 69.9 & 100.0 & 3.3 \\
\hline$>93$ & $74.7 \%$ & $25.3 \%$ & 48.8 & 95.4 & 74.7 & 87.0 & 4.0 \\
\hline$>95$ & $73.7 \%$ & $26.3 \%$ & 51.2 & 86.2 & 73.7 & 70.0 & 3.8 \\
\hline$>96$ & $76.5 \%$ & $23.5 \%$ & 61.0 & 80.0 & 76.5 & 65.8 & 4.3 \\
\hline$>97$ & $77.8 \%$ & $22.2 \%$ & 65.9 & 75.4 & 77.8 & 62.8 & 4.5 \\
\hline$>98$ & $81.6 \%$ & $18.4 \%$ & 78.0 & 61.5 & 81.6 & 56.1 & 5.4 \\
\hline$>99$ & $80.0 \%$ & $20.0 \%$ & 82.9 & 43.1 & 80.0 & 47.9 & 5.0 \\
\hline 100 & $85.7 \%$ & $14.3 \%$ & 92.7 & 27.7 & 85.7 & 44.7 & 7.0 \\
\hline \multicolumn{8}{|c|}{ Right Upper Lobe Fissure ( $N=|| 5)$} \\
\hline FCS & $\mathrm{CV}_{\text {neg }}$ & $\mathrm{CV}_{\text {pos }}$ & Sens & Spec & PPV & NPV & Number of Chartis Needed* \\
\hline$>75$ & $40.9 \%$ & $59.1 \%$ & 32.3 & 94.0 & 51.6 & 87.5 & 1.7 \\
\hline$>80$ & $56.0 \%$ & $44.0 \%$ & 43.1 & 96.1 & 56.0 & 90.3 & 2.3 \\
\hline$>83$ & $54.7 \%$ & $45.3 \%$ & 47.7 & 82.0 & 54.7 & 77.5 & 2.2 \\
\hline$>85$ & $58.2 \%$ & $41.8 \%$ & 56.9 & 78.0 & 58.2 & 77.1 & 2.4 \\
\hline$>90$ & $66.0 \%$ & $34.0 \%$ & 73.8 & 66.0 & 66.0 & 73.8 & 2.9 \\
\hline$>93$ & $69.6 \%$ & $30.4 \%$ & 78.5 & 64.0 & 69.6 & 73.9 & 3.3 \\
\hline$>95$ & $73.2 \%$ & $26.8 \%$ & 83.1 & 60.0 & 73.2 & 73.0 & 3.7 \\
\hline$>96$ & $73.0 \%$ & $27.0 \%$ & 84.6 & 54.0 & 73.0 & 70.5 & 3.7 \\
\hline$>97$ & $71.4 \%$ & $28.6 \%$ & 84.6 & 50.0 & 71.4 & 68.8 & 3.5 \\
\hline$>98$ & $73.3 \%$ & $26.7 \%$ & 87.7 & 44.0 & 73.3 & 67.1 & 3.8 \\
\hline$>99$ & $80.8 \%$ & $19.2 \%$ & 92.3 & 42.0 & 80.8 & 67.4 & 5.2 \\
\hline 100 & $81.3 \%$ & $18.8 \%$ & 95.4 & 26.0 & 81.3 & 62.6 & 5.3 \\
\hline \multicolumn{8}{|c|}{ Left Major Fissure $(\mathrm{N}=\mathbf{2 0 8})$} \\
\hline FCS & $C V_{\text {neg }}$ & $C V_{\text {pos }}$ & Sens & Spec & PPV & NPV & Number of Chartis Needed* \\
\hline$>80$ & $85.3 \%$ & $14.7 \%$ & 27.5 & 98.8 & 85.3 & 100.0 & 6.8 \\
\hline$>83$ & $86.1 \%$ & $13.9 \%$ & 32.5 & 99.4 & 86.1 & 92.9 & 7.2 \\
\hline$>85$ & $86.3 \%$ & $13.7 \%$ & 35.0 & 97.6 & 86.3 & 77.8 & 7.3 \\
\hline$>90$ & $88.2 \%$ & $11.8 \%$ & 45.0 & 97.6 & 88.2 & 81.8 & 8.5 \\
\hline$>93$ & $89.9 \%$ & $10.1 \%$ & 55.0 & 95.2 & 89.9 & 73.3 & 9.9 \\
\hline$>95$ & $91.1 \%$ & $8.9 \%$ & 62.5 & 91.7 & 91.1 & 64.1 & 11.3 \\
\hline$>96$ & $92.7 \%$ & $7.3 \%$ & 70.0 & 90.5 & 92.7 & 63.6 & 13.7 \\
\hline$>97$ & $93.5 \%$ & $6.5 \%$ & 75.0 & 85.7 & 93.5 & 55.6 & 15.4 \\
\hline$>98$ & $93.7 \%$ & $6.3 \%$ & 77.5 & 79.8 & 93.7 & 47.7 & 15.9 \\
\hline$>99$ & $93.8 \%$ & $6.2 \%$ & 80.0 & 72.0 & 93.8 & 40.5 & 16.1 \\
\hline 100 & $92.8 \%$ & $7.2 \%$ & 82.5 & 53.6 & 92.8 & 29.7 & 13.9 \\
\hline
\end{tabular}

Notes: Statistics per fissure and fissure completeness score regarding the sensitivity, specificity, positive and negative predictive value. Number of Chartis needed*: Number of Chartis measurements needed to identify one additional patient with collateral ventilation while applying this FCS.

Abbreviations: FCS, fissure completeness score; $\mathrm{CV}_{\text {pos }}$, presence of collateral ventilation; $\mathrm{CV}_{\text {neg, }}$ absence of collateral ventilation; sens, sensitivity; spec, specificity; PPV, positive predictive value; NPV, negative predictive value.

measurement. However, the outlined algorithm does not take into account any possible differences between the fissures. Our current study indicates that the left major fissure, being the only boundary between the two lobes, is more predictive than the
FCS of the right pulmonary fissures for the presence of collateral ventilation. Only a very high FCS of at least $95 \%$, and this only for the left major fissure, should actually be used to abstain from Chartis measurement. An individual example of 

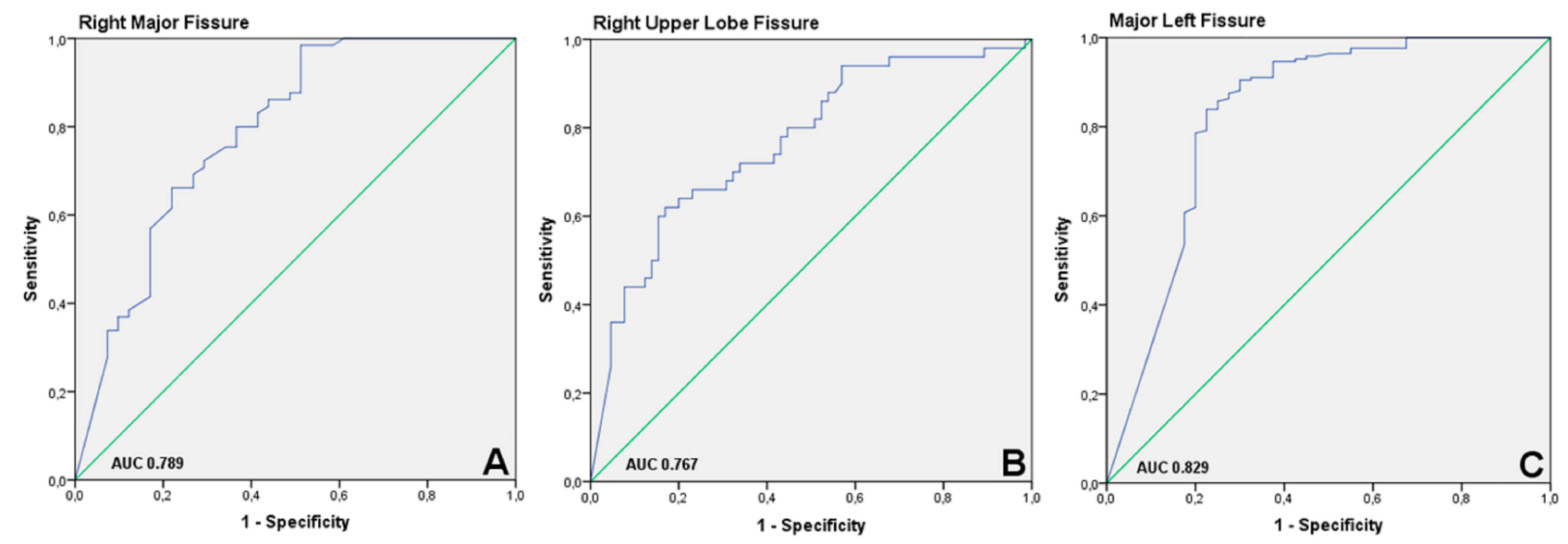

Figure 3 Receiver Operating Characteristic Curves. (A) Right major fissure: The area under the curve (AUC) is 0.789. (B) Right upper lobe fissure: The AUC is 0.767. (C) Left major fissure: The AUC is 0.829 .

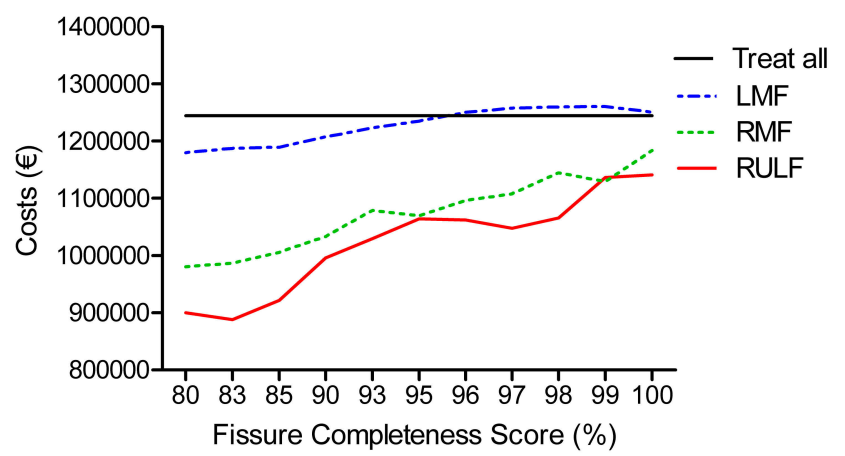

Figure 4 Cost analysis. Hypothetical graph of the costs of 100 patients for treatment with endobronchial valves. Costs: Endobronchial valve treatment in all patients without Chartis assessment: $€ 12.447$ per patient. Chartis measurement followed by treatment with valves: $€ 13.197$ per patient; Chartis assessment not followed by treatment: $€$ 3670.61 per patient. ${ }^{24}$ The "treat all" group indicates the costs of treating all 100 patients with a high FCS (indicated on $\mathrm{x}$-axis) and without Chartis assessment. In the other groups (RULF, LMF and RMF), Chartis measurement is performed in all patients, but patients are only treated with endobronchial valves if they are $\mathrm{CV}_{\text {neg. }}$.

Abbreviations: RULF, Right Upper Lobe Fissure; LMF, Left Major Fissure; RMF, Right Major Fissure.

a patient with a near-complete right major fissure and still collateral ventilation is provided in Figure 5.

Our data indicates that for the left major fissure, patients with FCS $<80 \%$ should be excluded from endobronchial valve treatment in the left lung without the need for further Chartis assessment. Regarding the right major fissure, all patients with an FCS below $90 \%$ had evidence of collateral ventilation and do not benefit from additional Chartis measurement. This is particularly interesting in the context that the FCS cut off of $90 \%$ suggested in previous clinical studies is too low to define a fissure as complete. ${ }^{2,14,18-20}$

The right upper lobe fissure is anatomically different from both major fissures, consisting of the minor and a part of the right major fissure. Our data shows that a few numbers of patients had no collateral ventilation with Chartis assessment even with an FCS of the right upper lobe below 75\%. It is not known why this difference exists between the right lung and the left lung. Possibly, the mechanism of collateral ventilation is slightly different. One possible explanation is the way the major and minor fissures are shaped. There is a lot of variation in the way the fissures are formed, as is indicated by two examples in Figure 6. Even with a nearcomplete fissure on quantitative CT scan, the way the fissures are merged may lead to a small gap and collateral ventilation.

The reason why there is no collateral ventilation, even with incomplete fissure may be due to the extent of disease of the pulmonary tissue. In emphysematous lungs, the resistance of the airways is much higher compared to healthy lungs. On the other hand, the resistance of the collateral channels is much lower in emphysematous lungs. Therefore, in emphysematous lungs, there is much more collateral flow over the collateral channels compared to healthy lungs. ${ }^{26}$ The mechanism of collateral ventilation between lobes through parenchymal bridges is unknown, but it is assumed that the mechanism might be the same as intralobar collateral ventilation. 9,27,28 Therefore, it can be hypothesized that in relatively healthy lung tissue there is no presence of collateral ventilation due to the high resistance of the collateral channels, but only in emphysematous lobes, with a low resistance of the collateral challenge. Thus, if collateral ventilation is measured in a relatively healthy right upper lobe, there may be no collateral ventilation due to the high resistance, even if the fissure is incomplete. This may also be the case in an emphysematous right upper lobe, but healthier middle and lower lobe. More research is needed to clarify this issue. 


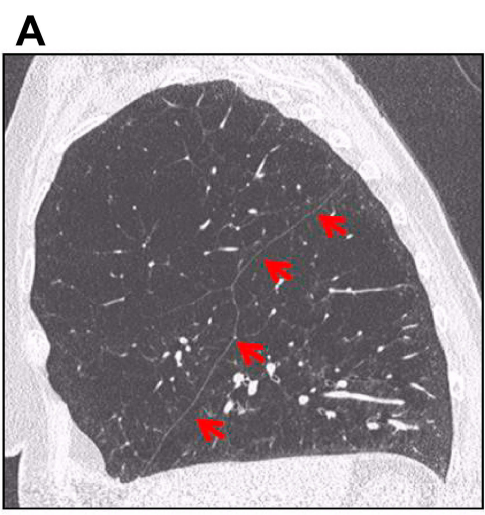

B

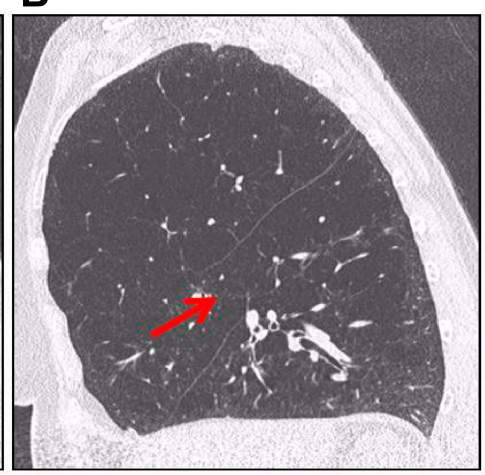

C

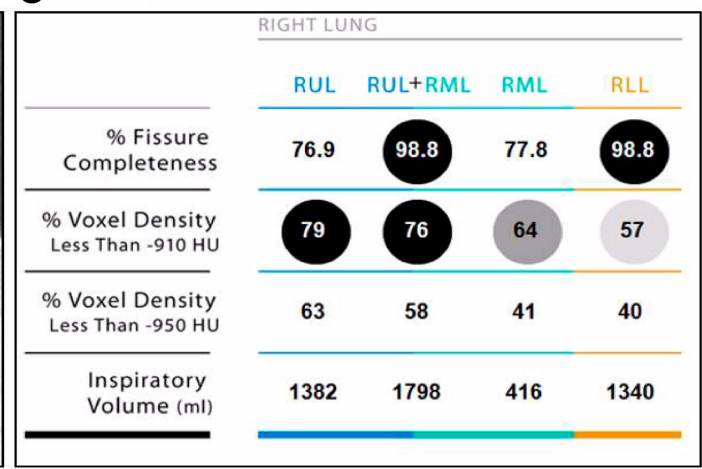

D

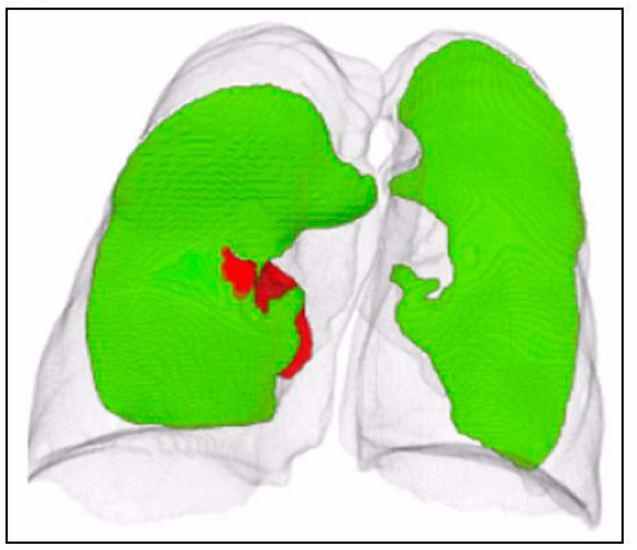

E

\begin{tabular}{|ll|}
\hline Assessment & RLL (Assessment \# 1) \\
Assessed Airway: & $\mathbf{2 2 : 3 3 : 2 9}$ \\
Assessment Start Time: & $\mathbf{0 2 : 2 9}$ \\
Assessment Duration: & $\mathbf{1 2 7 4} \mathbf{~ m L}$ \\
Total Exhaled Volume: & Accepted \\
Assessment Result: &
\end{tabular}

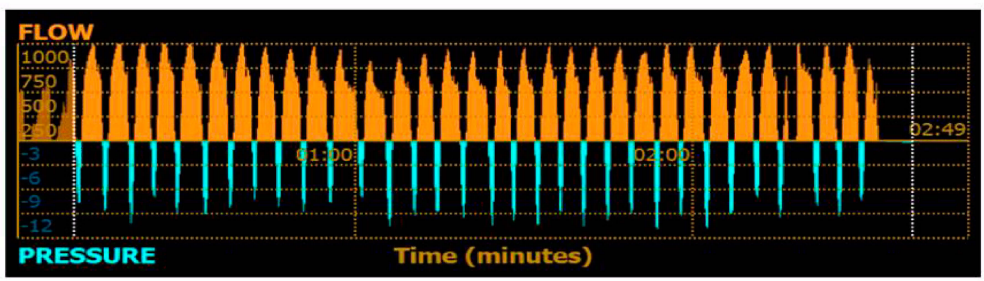

Figure 5 Example of a patient with heterogeneous severe emphysema, with a nearly complete right major fissure but with evidence of collateral ventilation in Chartis assessment. (A and B) Severe emphysema is located mainly in the right upper lobe. The fissure appears to be complete in A, but shows a small defect in figure B (arrow). (C) Results of the quantitative CT analysis of the right lung. Fissure completeness score of the right major fissure suggested a nearly complete fissure (98.8\%) for the right lower lobe. The right upper lobe fissure (76.9\%) and right middle lobe fissure (77.8\%) were quantified as less complete. (D) Visual representation of the fissure. The right side represents a complete left major fissure (green) without any gaps. The left side represents a nearly complete right major fissure (green) with minor gaps (red). (E) Chartis measurement of the right major fissure in the right lower lobe. It shows a persistent flow over time, as evidence of collateral ventilation through the major fissure.

Abbreviations: RUL, Right Upper Lobe; RML, Right Middle Lobe; RLL, Right Lower Lobe.

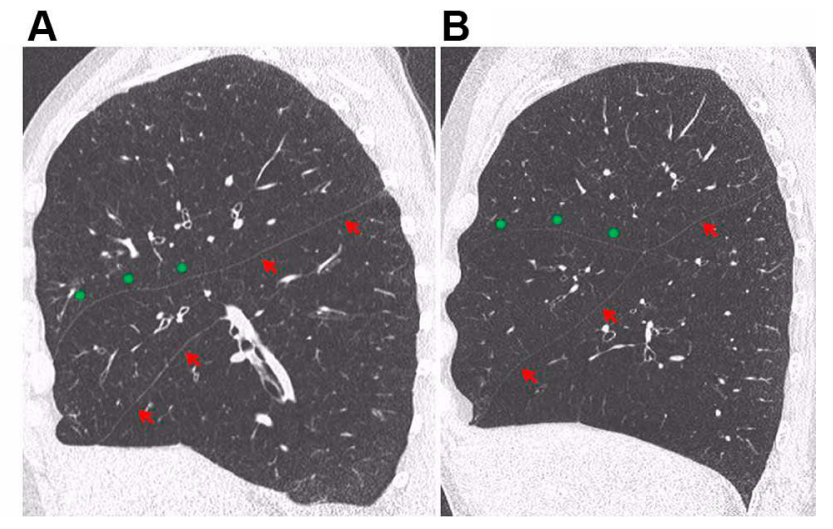

Figure 6 Formation of the right fissures. (A) The minor fissure (green dots) merges with a part of the right major fissure (red arrows). There is a gap between the superior and inferior part of the right major fissure, but the minor fissure is continuous with the superior part of the major fissure. (B) The major fissure is complete, the minor fissure merges with the major fissure.
Nevertheless, for the right upper lobe, this means that a lower threshold for the FCS should be employed to guide treatment decisions regarding the right upper lobe, and additional Chartis assessments are strongly encouraged if the right upper lobe is a good target but the fissures are incomplete.

For the upper limit threshold for the FCS, the necessity of an additional Chartis measurement can be based on two major considerations.

\section{Cost Aspect}

If patients with an FCS above a certain threshold would all be treated with endobronchial valves without performing an additional Chartis assessment, costs for the Chartis catheter would be saved. On the other hand, without Chartis measurement, 
a high number of patients would receive valves without effect, which is costly. Moreover, these valves may have to be removed, resulting in further bronchoscopies and hospital admissions. For more clarification, we performed a costsanalysis to compare the selection for treatment based on the fissure score alone to the combination of the FCS with Chartis measurement. For the right lung, all FCS should be combined with a Chartis measurement. For the left lung, patients can be treated based on an FCS $>95 \%$, without Chartis assessment. Basis for the calculations is costs and reimbursements in the Netherlands and will yield different thresholds in other countries.

\section{Number of Chartis Needed}

This represents the number of patients presumed to have complete fissures according to FCS, but have evidence of collateral ventilation in Chartis measurement. With the data from Table 3, it is shown in how many patients a Chartis needs to be performed to prevent one patient from inadvertently receiving valves while there is collateral ventilation. This consequence should be discussed with patients. We believe Chartis should always be performed in the right lung and for the left lung an FCS $>95 \%$ could be acceptable (Figure 7).

A low FCS indicates a high likelihood of presence of collateral ventilation. Potential target lobes with incomplete fissures are rarely chosen for endobronchial valve treatment. Therefore, outcome data in this setting are lacking. It has already been shown that treatment of patients with presence of collateral ventilation is not effective. ${ }^{18,21}$ We defined Chartis measurement as the most reliable predictor of success in endobronchial valve treatment since it functionally measures the

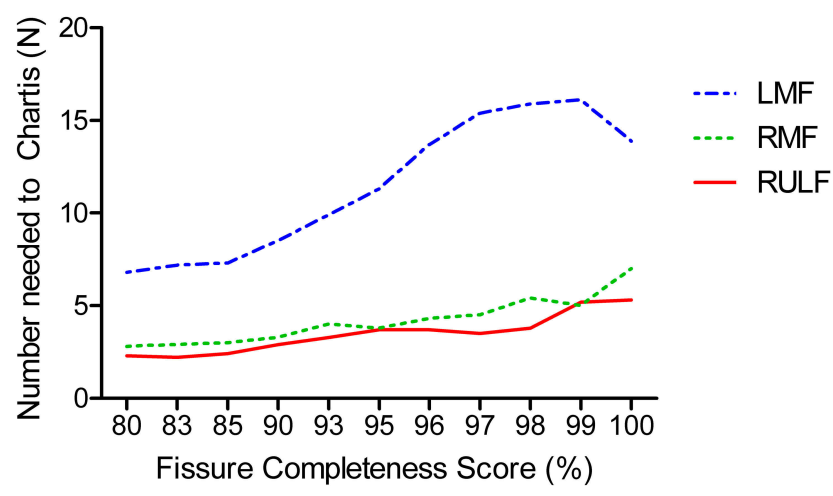

Figure 7 Number of Chartis measurements needed to identify one patient with collateral ventilation, by level of fissure completeness score. This score ranges from the indicated value on the $x$-axis to $100 \%$.

Abbreviations: RULF, Right Upper Lobe Fissure; LMF, Left Major Fissure; RMF, Right Major Fissure. collateral ventilation. Future studies may evaluate whether patients with a high FCS and low collateral flow may still benefit from treatment after treatment with endobronchial valves.

\section{Conclusion}

In conclusion, if a patient appears to be eligible for endobronchial valve treatment based on their CT scan, lung function and other characteristics, quantitative CT analysis for the FCS is a useful but imperfect tool to further select patients for endobronchial valve treatment. We strongly encourage the use of both the FCS and Chartis measurement as patient selection tools, and not the FCS alone, as is suggested in some recent literature.

Patients with incomplete fissures (FCS $<80 \%$ for left major fissure and FCS $<90 \%$ for right major fissure) can be excluded from endobronchial valve treatment and no Chartis measurement is needed.

In patients with (more) complete fissures, Chartis is always recommended in the right lung. For the left lung, Chartis assessments can optionally be omitted if the FCS is $>95 \%$.

\section{Disclosure}

KK reports presentation fee and travel support from Pulmonx Inc. TDK has nothing to disclose. CRG has nothing to disclose. DT has nothing to disclose. FD reports financial compensation for lectures for Pulmonx, Berlin-Chemie MENARINI, Roche Pharma AG and Bayer Vital GmbH. JS has nothing to disclose. HAMK reports an unrestricted research grant and fees for participation in advisory boards from GlaxoSmithKline, Boehringer Ingelheim, Novartis, AstraZeneca and Chiesi. DJS reports grants, personal fees, non-financial support from PulmonX Inc; PneumRx/BTG USA, and Nuvaira, USA, during the conduct of the study. RHH reports personal fees and grants from PulmonX Inc during the conduct of the study; and Head of Lungenemphysem Register e.V. (www.lungenemphy semregister.de). The authors report no other conflicts of interest in this work.

\section{References}

1. Valipour A, Slebos D, Herth F, et al. Endobronchial valve therapy in patients with homogeneous emphysema. results from the IMPACT study. Am J Respir Crit Care Med. 2016;194(9):1073-1082. doi:10.1164/rccm.201607-1383OC

2. Davey C, Zoumot Z, Jordan S, et al. Bronchoscopic lung volume reduction with endobronchial valves for patients with heterogeneous emphysema and intact interlobar fissures (the BeLieVeR-HIFi study): a randomised controlled trial. Lancet. 2015;386(9998):1066-1073. doi:10.1016/S0140-6736(15)60001-0 
3. Herth F, Noppen M, Valipour A, et al. Efficacy predictors of lung volume reduction with zephyr valves in a european cohort. Eur Respir J. 2012;39(6):1334-1342. doi:10.1183/09031936.00161611

4. Klooster K, Slebos DJ, Zoumot Z, Davey C, Shah PL, Hopkinson NS. Endobronchial valves for emphysema: an individual patient-level reanalysis of randomised controlled trials. BMJ Open Respir Res. 2017;4(1):e000214. doi:10.1136/bmjresp-2017-000214

5. Criner GJ, Sue R, Wright S, et al. A multicenter RCT of zephyr(R) endobronchial valve treatment in heterogeneous emphysema (LIBERATE). Am J Respir Crit Care Med. 2018;198(9):1151-1164.

6. Klooster K, Ten Hacken N, Hartman J, Kerstjens H, van Rikxoort E, Slebos D. Endobronchial valves for emphysema without interlobar collateral ventilation. $N$ Engl J Med. 2015;373(24):2325-2335. doi:10.1056/NEJMoa1507807

7. Klooster K, Hartman JE, Ten Hacken NH, Slebos DJ. One-year follow-up after endobronchial valve treatment in patients with emphysema without collateral ventilation treated in the STELVIO trial. Respiration. 2017;93(2):112-121. doi:10.1159/000453529

8. Kemp S, Slebos D, Kirk A, et al. A multicenter RCT of zephyr ${ }^{\circledR}$ endobronchial valve treatment in heterogeneous emphysema (TRANSFORM). Am J Respir Crit Care Med. 2017;196 (12):1535-1543. doi:10.1164/rccm.201707-1327OC

9. Koster T, Slebos D. The fissure: interlobar collateral ventilation and implications for endoscopic therapy in emphysema. Int J Chron Obstruct Pulmon Dis. 2016;11:765-773. doi:10.2147/COPD.S103807

10. Hartman JE, Vanfleteren LEGW, van Rikxoort EM, Slebos DJ, on behalf of the SOLVE consortium. Bronchoscopic lung volume reduction treatment using endobronchial valves for emphysema: emerging questions. Respiration. 2018;96(6):588-589. doi:10.1159/000491675

11. Van Der Molen MC, Klooster K, Hartman JE, Slebos DJ. Lung volume reduction with endobronchial valves in patients with emphysema. Expert Rev Med Devices. 2018;15(11):847-857. doi:10.1080/17434440.2018.1538780

12. Herth F, Slebos D, Criner G, Shah P. Endoscopic lung volume reduction: an expert panel recommendation - update 2017. Respiration. 2017;94(4):380-388. doi:10.1159/000479379

13. Slebos D, Shah P, Herth F, Valipour A. Endobronchial valves for endoscopic lung volume reduction: best practice recommendations from expert panel on endoscopic lung volume reduction. Respiration. 2017;93(2):138-150. doi:10.1159/000453588

14. Schuhmann M, Raffy P, Yin Y, et al. Computed tomography predictors of response to endobronchial valve lung reduction treatment. Comparison with chartis. Am J Respir Crit Care Med. 2015;191 (7):767-774. doi:10.1164/rccm.201407-1205OC

15. Koster T, van Rikxoort E, Huebner R, et al. Predicting lung volume reduction after endobronchial valve therapy is maximized using a combination of diagnostic tools. Respiration. 2016;92(3):150-157. doi:10.1159/000448849
16. Gompelmann D, Eberhardt R, Slebos D, et al. Diagnostic performance comparison of the Chartis system and high-resolution computerized tomography fissure analysis for planning endoscopic lung volume reduction. Respirology. 2014;19(4):524-530. doi:10.1111/resp.12253

17. Reymond E, Jankowski A, Pison C, et al. Prediction of lobar collateral ventilation in 25 patients with severe emphysema by fissure analysis with CT. AJR Am J Roentgenol. 2013;201(4):571-575. doi: $10.2214 /$ AJR. 12.9843

18. Sciurba FC, Ernst A, Herth FJ, et al. A randomized study of endobronchial valves for advanced emphysema. $N$ Engl J Med. 2010;363 (13):1233-1244. doi:10.1056/NEJMoa0900928

19. Criner GJ, Delage A, Voelker K, et al. Improving lung function in severe heterogenous emphysema with the spiration(R) valve system (EMPROVE): a multicenter, open-label, randomized, controlled trial. Am J Respir Crit Care Med. 2019;200(11):1354-1362. doi:10.1164/ rccm.201902-03830C

20. Li S, Wang G, Wang C, et al. The REACH trial: a randomized controlled trial assessing the safety and effectiveness of the spiration $(\mathrm{R})$ valve system in the treatment of severe emphysema. Respiration. 2018;1-12.

21. Herth F, Eberhardt R, Gompelmann D, et al. Radiological and clinical outcomes of using chartis ${ }^{\mathrm{TM}}$ to plan endobronchial valve treatment. Eur Respir J. 2013;41(2):302-308. doi:10.1183/09031936.00015312

22. Herzog D, Thomsen C, Poellinger A, et al. Outcomes of endobronchial valve treatment based on the precise criteria of an endobronchial catheter for detection of collateral ventilation under spontaneous breathing. Respiration. 2016;91(1):69-78. doi:10.1159/000442886

23. Gesierich W, Samitas K, Reicehberger F, Behr J. Collapse phenomenon during chartis collateral ventilation assessment. Eur Respir J. 2016;47(6):1657-1667. doi:10.1183/13993003.01973-2015

24. Hartman JE, Klooster K, Groen H, Ten Hacken NHT, Slebos DJ. Cost-effectiveness of endobronchial valve treatment in patients with severe emphysema compared to standard medical care. Respirology. 2018;23(9):835-841. doi:10.1111/resp.13295

25. Valipour A, Herth FJ, Burghuber OC, et al. Target lobe volume reduction and COPD outcome measures after endobronchial valve therapy. Eur Respir J. 2014;43(2):387-396. doi:10.1183/09031936. 00133012

26. Hogg J, Macklem P, Thurlbeck W. The resistance of collateral channels in excised human lungs. J Clin Invest. 1969;48(3):421-431. doi:10.1172/JCI105999

27. Gompelmann D, Eberhardt R, Herth F. Collateral ventilation. Respiration. 2013;85(6):515-520. doi:10.1159/000348269

28. Menkes H, Traystman R. Collateral ventilation. Am Rev Respir Dis. 1977;116(2):287-309. doi:10.1164/arrd.1977.116.2.287

International Journal of Chronic Obstructive Pulmonary Disease

\section{Publish your work in this journal}

The International Journal of COPD is an international, peer-reviewed journal of therapeutics and pharmacology focusing on concise rapid reporting of clinical studies and reviews in COPD. Special focus is given to the pathophysiological processes underlying the disease, intervention programs, patient focused education, and self management protocols. This journal is indexed on PubMed Central, MedLine and CAS. The manuscript management system is completely online and includes a very quick and fair peer-review system, which is all easy to use. Visit http://www.dovepress.com/testimonials.php to read real quotes from published authors. 